\title{
"ANALISIS PENGARUH LINGKUNGAN KERJA, KEPEMIMPINAN, DAN MOTIVASI TERHADAP KINERJA KARYAWAN ( STUDI PADA KARYAWAN BAGIAN KOLEKTOR PT CAKRAWALA CITRAMEGA MULTIFINANCE CABANG SEMARANG )"
}

\author{
Andy Praditya, Teguh Ariefiantoro, Edy Suryawardana
}

Fakultas Ekonomi Universitas Semarang

Diterima: Agustus 2019, Disetujui: September 2019, Dipublikasikan: Oktober 2019

\begin{abstract}
Humans are the most important resource in an organization, agency or company without human aspects, it is difficult for the organization to carry out the mission and objectives that have been set. It can also be said that if there are no human factors then the organization concerned is also not there because of the actors or objects to be addressed by an organization.This study aims to determine how much influence the work environment, leadership and motivation on the performance of employees of PT. Cakrawala Citramega Multifinance Cab. Semarang.The method of research analysis used is multiple linear regression methods. The sampling technique used is saturated sampling or census with a population of 30 collector employees.The results of hypothesis testing in this study indicate that the variables of work environment, leadership and motivation have a positive and significant influence on employee performance.
\end{abstract}

Keywords: Work Environment, Leadership, Motivation and Employee Performance.

\begin{abstract}
Abstrak
Manusia merupakan sumber daya terpenting dalam suatu organisasi, instansi atau perusahaan tanpa aspek manusia sulit kiranya organisasi untuk mengemban misi dan tujuan yang telah ditetapkan. Dapat dikatakan juga apabila faktor manusia tersebut tidak ada maka organisasi yang bersangkutan juga tidak ada karena pelaku atau objek yang hendak dituju oleh suatu organisasi. Penelitian ini bertujuan untuk mengetahui seberapa besar pengaruh lingkungan kerja, kepemimpinan dan motivasi terhadap kinerja karyawan kolektor PT. Cakrawala Citramega Multifinance Cab. Semarang. Metode analisis penelitian yang digunakan adalah metode regresi linier berganda. Teknik pengambilan yang digunakan yaitu sampling jenuh atau sensus dengan jumlah populasi sebanyak 30 karyawan kolektor. Hasil pengujian hipotesis dalam penelitian ini menunjukkan bahwa variabel lingkungan kerja, kepemimpinan dan motivasi terdapat pengaruh positif dan signifikan terhadap kinerja karyawan.
\end{abstract}

Kata Kunci : Lingkungan Kerja, Kepemimpinan, Motivasi dan Kinerja Karyawan. 


\section{PENDAHULUAN}

\section{Latar Belakang Masalah}

Di Era Globalisasi saat ini perusahaan di bidang penghasil barang maupun jasa dituntut untuk harus mampu dapat bersaing dengan perusahaan lainnya. Di dalam bersaing dengan pesaing yang semakin ketat saat ini, maka keunggulan-keunggulan yang dimiliki diharapkan dapat di pertahankan, diperbaharui dan di tingkatkan lagi. Selain itu setiap kelemahan yang dimiliki oleh perusahaan saat ini wajib untuk diperbaiki ataupun dihilangkan. Dengan adanya hal ini diharapkan dapat meningkatkan tujuan dan optimalisasi dari apa yang telah menjadi tujuan dari perusahaan. Dengan upaya memaksimalkan dan mengoptimalkan sumber daya yang dimiiki oleh perusahaan.

PT. Cakrawala Citramega Multifinance mulai beroperasi pada tahun 2003 di Jakarta. Sejak beroperasi PT. Cakrawala Citramega Multifinance berkomitmen untuk memberi pelayanan yang terbaik untuk masyarakat luas dengan produk yang sesuai dengan ketentuan Otoritas Jasa Keuangan (OJK) antara lain seperti pembiayaan dibidang otomotif dan lebih khusus pada pemberian kredit kendaraan bermotor (Baru / Bekas) dan akan diperluas ke pembiayaan multiguna. Sumber Daya Manusia (SDM) merupakan aset yang sangat penting bagi suatu organisasi, mereka memiliki peran aktif sebagai pelaku organisasi maupun perencanaan di dalam setiap aktivitas organisasi. Setiap karyawan memiliki pemikiran, perasaan, keinginan, status, latar belakang pendidikan, usia, dan jenis kelamin yang heterogen dibawa kedalam suatu organisasi untuk bekrjasama untuk mencapai tujuan perusahaan. Fungsi dari bagian-bagian organisasi tergantung pada kemampuan manusia dan organisasi yang bersangkutan untuk mengarahkan organisasi menuju tujuan target yang telah ditetapkan oleh perusahaan. Tercapai atau tidaknya tujuan tergantung pada karyawan yang ada di organisasi. Dengan adanya kualitas SDM yang tinggi maka akan menghasilkan kinerja yang tinggi bagi organisasi dan dapat memberikan kontribusi yang maksimal bagi perusahaan.

Berdasarkan fenomena yang terjadi dilapangan menunjukkan bahwa kinerja karyawan bagian kolektor di PT. Cakrawala Citramega Multifinance Semarang terjadi penurunan hasil penagihan yang kurang maksimal. Dengan tingginya tujuan kinerja yang optimal, maka hambatan untuk mencapai kinerja yang diinginkan juga semakin 
tinggi, maka PT. Cakrawala Citramega Multifinance mengukur kinerja karyawan dengan mengukur indikator target collection, dengan adanya target collection perusahaan dapat melihat kinerja karyawan dalam pencapaian collection, sehingga target yang telah ditetapkan dapat di lihat oleh perusahaan sudah dicapai atau tidak.

\section{Tujuan Penelitian}

1. Untuk menganalisis pengaruh Lingkungan Kerja terhadap Kinerja Karyawan bagian Kolektor PT. Cakrawala Citramega Multifinance Cab. Semarang

2. Untuk menganalisis pengaruh Kepemimpinan terhadap Kinerja Karyawan bagian Kolektor PT. Cakrawala Citramega Multifinance Cab. Semarang

3. Untuk menganalisis pengaruh Motivasi Kerja terhadap Kinerja Karyawan bagian Kolektor PT. Cakrawala Citramega Multifinance Cab. Semarang

\section{TINJAUAN PUSTAKA}

\section{Kinerja Karyawan}

Suatu organisasi tentu membutuhkan karyawan yang berkualitas. Untuk mencapai hal tersebut, maka perlu memperhatikan banyak hal yang berkaitan dengan kinerjanya. Menurut A.A Anwar Prabu Mangkunegara (2017) Kinerja adalah hasil kerja secara kualitas dan kuantitas yang dicapai oleh seseorang pegawai dalam melaksanakan tugasnya sesuai dengan tanggung jawab yang diberikan kepadanya.

\section{Lingkungan Kerja}

Menurut Heny Sidanti (2015) Lingkungan kerja merupakan salah satu faktor penting dalam menciptakan kinerja karyawan.Karena lingkungan kerja mempunyai pengaruh langsung terhadap karyawan didalam menyelesaikan pekerjaan yang pada akhirnya akan meningkatkan kinerja organisasi. Suatu kondisi lingkungan kerja dikatakan baik apabila karyawan dapat melaksanakan kegiatan secara optimal, sehat, aman, dan nyaman. Oleh karena itu penentuan dan penciptaan lingkungan kerja yang baik akan sangat menentukan keberhasilan pencapaian tujuan organisasi. Sebaliknya apabila lingkungan kerja yang tidak baik akan dapat menurunkan motivasi serta semangat kerja dan akhirnya dapat menurunkan kinerja karyawan. 


\section{Kepemimpinan}

Menurut Aurelia Potu (2013) Kepemimpinan adalah seorang pribadi yang memiliki superioritas tertentu, sehingga ia memiliki kewajiban dan kekuasaan untuk menggerakkan orang lain melakukan usaha bersama guna mencapai suatu tujuan tertentu. Proses kepemimpinan melibatkan keinginan dan niat, keterlibatan yang aktif antara pemimpin dan bawahan untuk mencapai tujuan yang diinginkan bersama.

\section{Motivasi}

Menurut Analisa (2011) Motivasi adalah pemberian kegairahan bekerja kepada karyawan. Keadaan dalam pribadi seseorang yang mendorong keinginan individu untuk melakukan kegiatan- kegiatan tertentu guna tujuan. Dengan pemberian motivasi dimaksudkan pemberian daya perangsang kepada karyawan yang bersangkutan agar karyawan tersebut bekerja dengan segala upayanya. Dengan demikian motivasi merupakan pendorong agar seseorang itu melakukan suatu kegiatan untuk mencapai tujuan

\section{Hubungan Lingkungan Kerja dengan Kinerja Karyawan $\left(\mathrm{H}_{1}\right)$}

Menurut Diana Khairani Sofyan (2013) Faktor-Faktor lingkungan kerja antara lain : Suara bising, penerangan tempat kerja, kelembaban dan suhu udara, pelayanan kebutuhan karyawan, penggunaan warna, kebersihan lingkungan. Faktor-faktor yang mempengaruhi kinerja seseorang adalah: Karakteristik lingkungan kerja, Karakteristik Pekerjaan dan Peralatan, Ketegangan Psikologis, Prosedur Pekerjaan dan Ketegangan Fisik. Sherren Delani Muntu dkk (2018) yang menunjukkan bahwa Lingkungan Kerja memiliki hubungan pengaruh positif dan signifikan terhadap Kinerja Karyawan.

\section{Hubungan Kepemimpinan dengan Kinerja Karyawan $\left(\mathbf{H}_{2}\right)$}

Sutrisno (2011) menyatakan bahwa kepemimpinan sebagai proses mengarahkan dan mempengaruhi aktivitas yang berkaitan dengan tugasdari para anggota kelompok. Dari beberapa pendapat diatas dapat disimpulkan bahwa kepemimpinan adalah kemampuan seorang pemimpin dalam proses untuk mempengaruhi dan mengarahkan aktivitas yang berkaitan dengan tugas dari para anggota organisasi secara efektif. Penelitian yang dilakukan oleh I Nyoman Jaka Alit Wiratama dan Desak Ketut Sintaasih (2013) yang menunjukkan bahwa Kepemimpinan memiliki hubungan pengaruh positif dan signifikan terhadap Kinerja Karyawan. 


\section{Hubungan Motivasi dengan Kinerja Karyawan $\left(\mathrm{H}_{3}\right)$}

Menurut Heny Sidanti (2015) Motivasi ialah suatu model dalam menggerakkan dan mengarahkan parakaryawan agar dapat melaksanakan tugasnya masing-masing dalam mencapaisasaran dengan penuh kesadaran, kegairahan dan bertanggung jawab. Jadi motivasi kerja adalah sesuatu yang menimbulkan semangat atau dorongan kerja, Oleh karena itu, motivasi kerja dalam psikologi biasa disebut pendorong semangat kerja. Penelitian yang dilakukan oleh Andrian Daniel Johny Tri Sasongko (2016) yang menunjukkan bahwa Motivasi memiliki hubungan pengaruh positif dan signifikan terhadap Kinerja Karyawan.

\section{Kerangka Pemikiran}

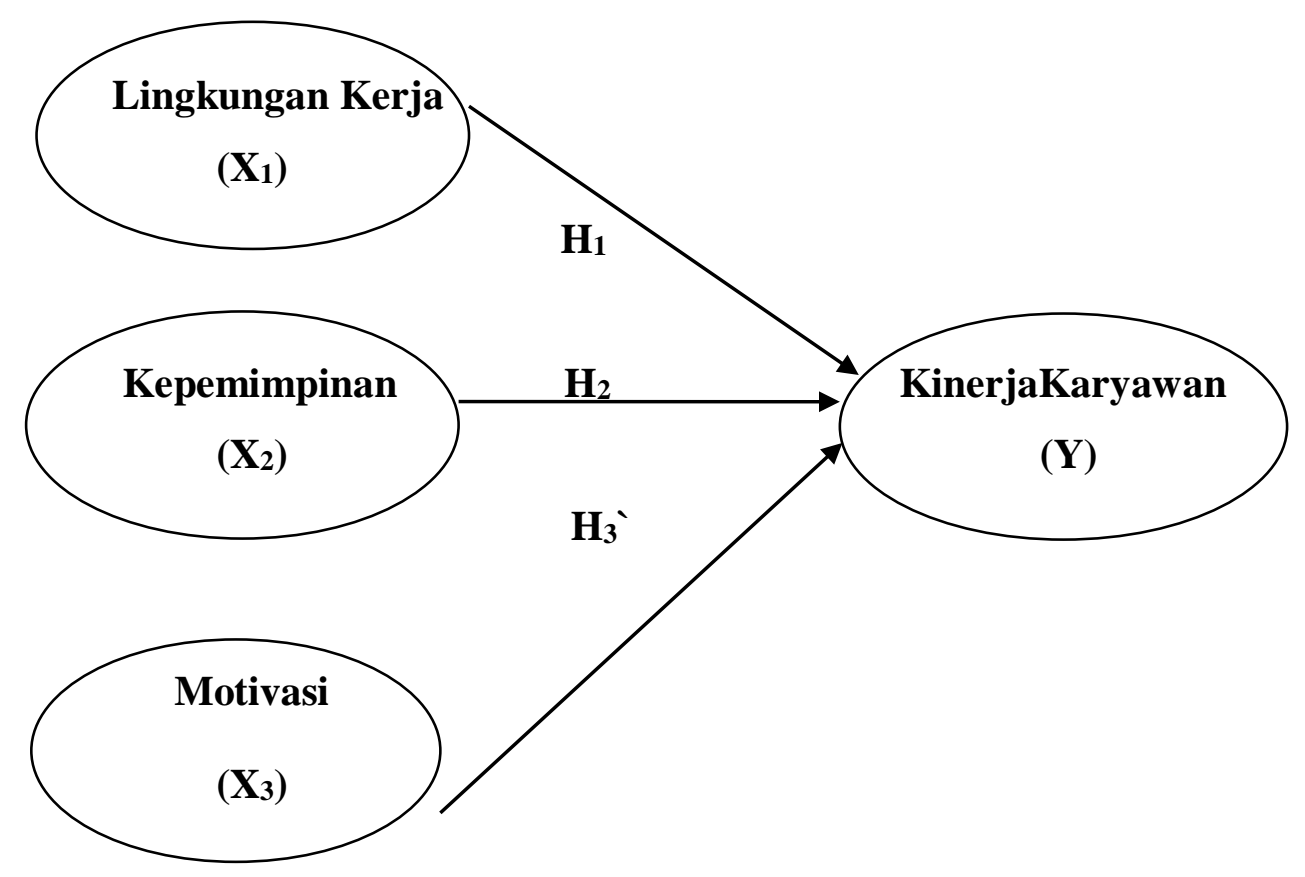

Gambar 1

Kerangka Pemikiran Penelitian

Sumber : Dari fenomena dan hasil penelitian terdahulu

\section{METODOLOGI PENELITIAN}

\section{Jenis Penelitian}

Dalam penelitian ini adalah data primer. Dalam Beverly M. O. Pua, dkk (2017) data primer yaitu data yang diperoleh secara langsung meliputi dokumen-dokumen 
perusahaan berupa sejarah perkembangan perusahaan, struktur organisasi dan lain - lain yang berhubungan dengan penelitian.

\section{Populasi dan Sampel}

Sampel pada penelitian ini adalah semua populasi karyawan Kolektor di PT. Cakrawala Citramega Multifinance Cab.Semarang dari tahun 2016 - 2018 yang berjumlah 30 karyawan. Dalam Teknik pengambilan sampel yang digunakan adalah sampling jenuh atau sensus yaitu teknik penentuan sampel dimana semua anggota populasi digunakan sebagai sampel.

\section{Metode Pengumpulan Data}

Dalam penelitian ini menggunakan beberapa metode pengumpulan data diantaranya sebagai berikut :

1. Kuesioner

Dalam mengadakan kuesioner penulis mengajukan beberapa pertanyaan secara tertulis kepada responden yaitu karyawan kolektor di PT Cakrawala Citramega Multifinance Cab. Semarang

2. Studi Pustaka

Menggali dari buku-buku pustaka yang berhubungan dengan penelitian terkait.

\section{Definisi dan Pengukuran Variabel}

1. Lingkungan kerja $\left(\mathrm{X}_{1}\right)$ Menurut Heny Sidanti (2015) Lingkungan kerja merupakan salah satu faktor penting dalam menciptakan kinerja karyawan. Indikator : pengawasan, suasana kerja, perlakuan dengan baik, adanya rasa aman dari para pegawai, hubungan berlangsung secara serasi dan para pegawai mendapat perlakuan secara adil dan objektif.

2. Kepemimpinan $\left(\mathrm{X}_{2}\right)$, Menurut I Nyoman Jaka Alit Wiratama, Desak Ketut Sintaasih (2013) kepemimpinan adalah kemampuan seorang pemimpin dalam proses untuk mempengaruhi dan mengarahkan aktivitas yang berkaitan dengan tugas dari para anggota organisasi secara efektif. Indikator : kejelasan pemimpin dalam member perintah, pandai membaca situasi dan peka terhadap saran dan masukan, pemberian penghargaan, teguran maupun ujian.

3. Motivasi $\left(\mathrm{X}_{3}\right)$, Menurut A.A. Anwar Prabu Mangkunegara (2017) Motivasi kerja didefinisikan sebagai kondisi yang berpengaruh membangkitkan, mengarahkan 
dan memelihara perilaku yang berhubungan dengan Kinerja karyawan. Indikator : tanggung jawab dalam melaksanakan tugas, melaksanakan tugas dengan target yang jelas, ada umpan balik atas hasil pekerjaannya, bekerja dengan harapan ingin memperoleh perhatian dari teman dan atasan.

4. Kinerja (Y), Menurut A.A Anwar Prabu Mangkunegara (2017) Kinerja adalah hasil kerja secara kualitas dan kuantitas yang dicapai oleh seseorang pegawai dalam melaksanakan tugasnya sesuai dengan tanggung jawab yang diberikan kepadanya. Indikator : kuantitas, kualitas, ketepatan waktu, kehadiran, kemampuan bekerjasama.

\section{Metode Analisis}

\section{Uji Validitas}

Uji validitas dilakukan untuk mengukur sah atau valid tidaknya suatu kuesioner, menurut Imam Ghozali (2011:52) validitas adalah bukti bahwa instrumen, teknik, atau proses yang digunakan untuk mengukur sebuah konsep benar-benar mengukur konsep yang dimaksudkan. Suatu kuesioner dikatakan valid apabila pertanyaaan pada kuesioner mampu mengungkapkan sesuatu yang akan diukur oleh kuesioner tersebut.

\section{Uji Reliabilitas}

Menurut Imam Ghozali (2011:47) uji reliabilitas adalah alat untuk mengukur suatu kuesioner yang merupakan indikator-indikator dari variabel atau konstruk.

\section{Uji Multikolinearitas}

Uji multikolinieritas bertujuan menguji apakah dalam model regresi ditemukan adanya korelasi antar variabel bebas. Model regresi yang baik seharusnya tidak terjadi korelasi diantara variabel bebas jika variabel bebas berkorelasi maka variabel-variabel ini tidak ortogonal. Variabel ortogonal adalah variabel bebas yang nilai korelasi antar sesama variabel bebas $=0$. Multikolinieritas dapat dilihat dari nilai Tolerance dan Variance Inflation Factor (VIF).

\section{Uji Heteroskedastisitas}

Uji Heteroskedastisitas bertujuan menguji apakah dalam model regresi terjadi ketidaksamaan variance dari residual satu pengamatan ke pengamatan lain tetap, disebut Homoskedastisitas dan jika berbeda disebut Heteroskedastisitas. Model regresi yang 
baik adalah yang Homoskedastisitas atau tidak terjadi Heteroskedastisitas (Ghozali,2013).

\section{Uji Normalitas}

Uji normalitas bertujuan untuk menguji apakah dalam model regresi, variabel pengganggu atau residual memiliki distribusi normal (Ghozali,2013).

\section{Analisis Regresi Linear Berganda}

Teknik analisis data yang digunakan untuk memecahkan permasalahan dalam penelitian ini adalah menggunakan analisis regresi linier berganda (Salju, 2014). Analisis ini dipergunakan untuk mengetahui dan memperoleh gambaran mengenai pengaruh Lingkungan Kerja $\left(\mathrm{X}_{1}\right)$, Kepemimpinan $\left(\mathrm{X}_{2}\right)$ Motivasi Kerja $\left(\mathrm{X}_{3}\right)$ yang secara parsial mempunyai pengaruh yang signifikan terhadap Kinerja $\operatorname{Karyawan}(\mathrm{Y})$. Pengolahan data dalam penelitian ini dilakukan dengan program komputer Statistical Package for Social Science (SPSS).

Model regresi linear berganda untuk menguji hipotesis adalah sebagai berikut :

$$
\begin{array}{ll}
\boldsymbol{Y}=\boldsymbol{\alpha}+\boldsymbol{\beta} \boldsymbol{X} \mathbf{1}+\boldsymbol{\beta} \boldsymbol{X} \mathbf{2}+\boldsymbol{\beta} \boldsymbol{X} \mathbf{3}+\boldsymbol{e} \ldots(\mathbf{1}) \\
\text { Keterangan } \\
\mathrm{Y} \quad \text { : Kinerja Karyawan } \\
\alpha \quad \text { : Konstanta } \\
\mathrm{X} 1 \quad \text { : Lingkungan Kerja } \\
\mathrm{X} 2 \quad \text { : Kepemimpinan } \\
\mathrm{X} 3 \quad \text { : Motivasi } \\
\mathrm{e} \quad \text { : Eror } \\
\beta \quad \text { : Beta (koefisien regresi) }
\end{array}
$$

\section{Uji Hipotesis}

Uji hipotesis adalah metode pengambilan keputusan yang didasarkan dari analisis data. Pengujian hipotesis berhubungan dengan penerimaan atau penolakan suatu hipotesis. Pengujian yang digunakan untuk mendukung uji hipotesis adalah uji parsial (uji t).

\section{Uji Parsial (Uji t)}

Menurut Ghozali (2016:171) Uji statistik t pada dasarnya menunjukkan seberapa jauh pengaruh satu variabel penjelas/independen secara individual dalam menerangkan 
variasi variabel dependen. Pengujian secara parsial terhadap model regresi dilakukan dengan menggunakan Uji t, menggunakan taraf kepercayaan 95\% yang memperlihatkan bahwa tingkat kesalahan yang diizinkan hanyalah sebesar $5 \%(a=0,05)$.

\section{Uji Kelayakan Model (Uji F)}

Menurut Ghozali (2016:96) uji statistik F pada dasarnya menunjukkan apakah model regresi dari variabel independen (bebas) variabel dependen (terikat) layak untuk dilakukan uji selanjutnya. Hasil uji F dilihat dengan membandingkan nilai (pada kolom sig.) dalam tabel ANOVA dengan level of significant $(\alpha=0,05)$ yaitu :

a. Jika p-value (pada kolom sig.) <level of significant $(0,05)$ maka model regresi layak digunakan.

b. Jika p-value (pada kolom sig.) >level of significant $(0,05)$ maka model regresi tidak layak digunakan.

\section{Uji Koefisien Determinasi $\left(\mathbf{R}^{2}\right)$}

Menurut Ghozali (2016:95) koefisien determinasi $\left(\mathrm{R}^{2}\right)$ pada intinya mengukur seberapa jauh kemampuan model dalam menerangkan variasi variabel dependen. Nilai koefisien determinasi adalah antara 0 dan 1 . Nilai $\mathrm{R}^{2}$ yang kecil berarti kemampuan variabelvariabel independen dalam menjelaskan variasi variabel dependen amat terbatas. $\left(\mathrm{R}^{2}\right)$ atau disebut juga adjusted $R^{2}$ memiliki tolak ukur nilai diantara $0-1$, nilai yang semakin mendekati 1 berarti hasil penelitian menunjukan pengaruh yang semakin kuat atau variabel - variabel independen memebrikan hampir semua informasi yang dibutuhkan untuk memprediksi variasi variabel dependen, dan jika semakin mendekati 0 berarti pengaruh variabel independen (bebas) terhadap variebel terikat menunjukan semakin lemah.

\section{HASIL PENELITIAN DAN PEMBAHASAN}

\section{Hasil Uji Validitas dan Reliabilitas}

\section{Uji Validitas}

Dari hasil uji validitas menunjukkan bahwa semua item indikator tersebut dinyatakan valid karena nilai $r_{\text {hitung }}$ lebih besar dari pada nilai $r_{\text {tabel }}$, yaitu lebih besar dari 0,20 dengan tingkat signifikansi lebih kecil dari 0,05. 


\section{Uji Reliabilitas}

Hasil uji reliabilitas dari $\mathrm{X} 1=0,751, \mathrm{X} 2=0.796, \mathrm{X} 3=0.749$, dan $\mathrm{Y}=0.814$, menunjukkan bahwa semua variabel mempunyai nilai Cronbach'c Alpha lebih besar dari batas yang ditentukan yaitu sebesar 0,70.

\section{Analisis Regresi Linier Berganda}

Analisis regresi linier berganda adalah pengujian hipotesis yang digunakan untuk mengetahui pengaruh antara variabel bebas, yaitu lingkungan kerja $\left(\mathrm{X}_{1}\right)$, kepemimpian $\left(\mathrm{X}_{2}\right)$, dan motivasi $\left(\mathrm{X}_{3}\right)$, terhadap variabel terikat yaitu kinerja karyawan $(\mathrm{Y})$. Berikut hasil pengujian regresi linier berganda dengan dibantu program SPSS dalam proses penghitungannya sebagai berikut:

\section{Hasil Analisis Regresi Linier Berganda}

Coefficients $^{\mathrm{a}}$

\begin{tabular}{|c|c|c|c|c|c|c|}
\hline \multirow{2}{*}{\multicolumn{2}{|c|}{ Model }} & \multicolumn{2}{|c|}{$\begin{array}{l}\text { Unstandardized } \\
\text { Coefficients }\end{array}$} & $\begin{array}{l}\text { Standardized } \\
\text { Coefficients }\end{array}$ & \multirow[t]{2}{*}{$\mathrm{t}$} & \multirow[t]{2}{*}{ Sig. } \\
\hline & & $\mathrm{B}$ & Std. Error & Beta & & \\
\hline \multirow{5}{*}{1} & (Constant) & 8,134 & 2,901 & & 2,804 & , 009 \\
\hline & Lingkungan & ,403 & , 149 & ,324 & 2,701 & ,012 \\
\hline & Kerja & & & & & \\
\hline & Kepemimpinan &, 543 &, 173 & ,379 & 3,129 & ,004 \\
\hline & Motivasi & ,536 & , 192 & ,348 & 2,788 &, 010 \\
\hline
\end{tabular}

a. Dependent Variable: Kinerja Karyawan

Sumber: Data primer yang diolah, 2019

Kinerja Karyawan = 0,324 $($ Lingkungan Kerja $)+$ 0,379 $($ Kepemimpinan $)+$ 0,348 (Motivasi)

Hasil persamaan regresi tersebut di atas dapat diartikan sebagai berikut:

1. Variabel lingkungan kerjaberpengaruh positif dan signifikan. Semakin baik lingkungan kerja maka kinerja akan semakin meningkat.

2. Variabel kepemimpinan berpengaruh positif dan signifikan. Semakin baik kepemimpinan maka kinerja akan semakin meningkat.

3. Variabel motivasi berpengaruh positif dan signifikan. Semakin baik motivasi maka kinerja akan semakin meningkat. 


\section{Hasil Uji F}

Uji F pada dasarnya menunjukkan apakah semua variabel independen atau bebas yang dimasukkan dalam model mempunyai pengaruh secara bersama-sama terhadap variabel dependen atau terikat (Ghozali, 2012).

\section{Hasil Uji F}

\begin{tabular}{l} 
ANOVA \\
\begin{tabular}{|ll|l|l|l|l|l|}
\hline Model & $\begin{array}{l}\text { Sum } \\
\text { Squares }\end{array}$ & of & Df & Mean Square & F & Sig. \\
\hline \multirow{2}{*}{1} & Regression & 368,486 & 3 & 122,829 & 26,419 &, $000^{\mathrm{b}}$ \\
\hline & Residual & 120,881 & 26 & 4,649 & & \\
\hline
\end{tabular} \\
\hline
\end{tabular}

a. Dependent Variable: Kinerja Karyawan

b. Predictors: (Constant), Motivasi, Lingkungan Kerja, Kepemimpinan

Sumber: Data primer yang diolah, 2019

Berdasarkan hasil uji F pada tabel di atas, menunjukkan nilai $F_{\text {hitung }}$ sebesar 26,419 dengan probabilitas signifikansi sebesar 0,000. Karena probabilitas signifikansinya kurang dari 0,05, maka $\mathrm{H}_{0}$ ditolak dan Ha diterima. Yang berarti dapat dikatakan bahwa lingkungan kerja, kepemimpian, dan motivasi berpengaruh secara simultan terhadap kinerja karyawan

\section{Hasil Koefisien Determinasi $\left(\mathbf{R}^{2}\right)$}

\section{Hasil Uji Determinasi}

\section{Model Summary ${ }^{\mathrm{b}}$}

\begin{tabular}{|l|l|l|l|l|}
\hline Model & $\mathrm{R}$ & $\mathrm{R}$ Square & $\begin{array}{l}\text { Adjusted R } \\
\text { Square }\end{array}$ & $\begin{array}{l}\text { Std. Error of } \\
\text { the Estimate }\end{array}$ \\
\hline 1 &, $868^{\mathrm{a}}$ &, 753 &, 724 & 2,156 \\
\hline
\end{tabular}

a. Predictors: (Constant), Motivasi, Lingkungan Kerja,

Kepemimpinan

b. Dependent Variable: Kinerja Karyawan

Berdasarkan hasil perhitungan pada tabel di atas, menunjukkan bahwa nilai Adjusted RSquere yang diperoleh sebesar 0,724. Dalam hal ini berarti 72,4\% variasi variabel kinerja karyawan dijelaskan oleh variabel lingkungan kerja, kepemimpian, dan motivasi. Sedangkan sisanya 27,6\% dijelaskan oleh variabel lain di luar model. 


\section{PENUTUP}

\section{Kesimpulan}

Berdasarkan hasil penelitian yang telah dilakukan dan dibahas pada bab sebelumnya, maka penulis dapat simpulkan sebagai berikut :

1. Hasil penelitian menaunjukkan bahwa lingkungan kerja berpengaruh positif dan signifikan terhadap kinerja karyawan PT. Cakrawala Citramega Multifinance Cab Semarang.

2. Hasil penelitian menunjukkan bahwa kepemimpinan berpengaruh positif dan signifikan terhadap kinerja karyawan PT. Cakrawala Citramega Multifinance Cab Semarang.

3. Hasil penelitian menunjukkan bahwa motivasi berpengaruh positif dan signifikan terhadap kinerja karyawan PT. Cakrawala Citramega Multifinance Cab Semarang.

\section{Saran}

Berdasarkan simpulan penelitian diatas, maka saran yang dapat disampaikan adalah sebagai berikut :

1. Pihak Manajemen lebih memonitoring kehadiran karyawan disetiap harinya, khususnya di devisi marketing (kolektor)

2. Memberikan beban tagih atau target kerja yang merata kepada kolektor. Guna memberikan pemerataan keadilan target dalam bekerja.

3. Membudayakan perlakuan tutur kata dan sikap yang baik terhadap bawahan maupun atasan.

4. Lebih meningkatkan komunikasi yang lebih intens dan jelas guna memksimalkan perintah yang diberikan oleh atasan kepada bawahan.

5. Setiap kolektor di wajibkan berkomitmen terhadap beban tagih dan target yang diberikan olen pihak manajemen.

6. Karyawan diharapkan memiliki dorongan guna untuk memenuhi kebutuhan akan kehidupannya dan prestasi kerja.

7. Lebih meningkatkan bonus atau insentif yang lebih tinggi terhadap kolektor guna memberikan motivasi lebih untuk meningkatkan kinerja karyawan. 


\section{DAFTAR PUSTAKA}

Fahmi, I. (2018). Manajemen Kinerja. Bandung: ALFABETA.

Handoko, T. H. (2011). Manajemen (Kedua ed.). Yogyakarta: BPFE-YOGYAKARTA.

Hasibuan, M. S. (2018). Manajemen Sumber Daya Manusia. Jakarta: PT. Bumi Aksara.

Mahmudi. (2010). Manajemen Kinerja Sektor Publik (Kedua ed.). Yogyakarta: Sekolah Tinggi Ilmu Manajemen YKPN.

Mangkunegara, A. P. (2017). Manajemen Sumber Daya Manusia Perusahaan. Bandung: PT Remaja Rosdakarya.

Mulyadi, D., \& Amanda, S. (2015). Pengaruh Kepemimpinan Dan Motivasi Kerja Terhadap Kinerja Karyawan di Bank BJS Syariah Cabang Bogor. Binaniaga, 11 (2), 33-38.

Potu, A. (2013). Kepemimpina dan Lingkungan Kerja Pengaruhnya Terhadap Kinerja Karyawan Kanwil Ditjen Kekayaan Sulutenggo Utara di Manado. Manajemen, 1 (4), 2303-1174.

Putra, I. K., \& Subudi, M. (2015). Pengaruh Gaya Kepemimpinan Transformasional Dan Lingkungan Kerja Fisik Terhadap Kinerja Karyawan PT BPR Pedungan. Manajemen , 4 (10), 3146-3171.

Qodri Z, M. L. (2015). Human Resource Division HRD \& GA General Affair. Jakarta: Raih Asa Sukses (Penebar Swadaya Grup).

Sidanti, H. (2015). Pengaruh Lingkungan Kerja, Disiplin Kerja Dan Motivasi. Manajemen, 9 (1), 44-53.

Sofyan, D. K. (2013). Pengaruh Lingkungan Kerja Terhadap Kinerja Kerja Pegawai BAPPEDA. Industrial Engineering , 2 (1), 18-23.

Sudarmanto. (2009). Kinerja dab Pengembangan Kompetensi SDM. Yogyakarta: PUSTAKA PELAJAR.

Suhardi. (2018). Pengantar Manajemen \& Aplikasinya. Yogyakarta: Gava Media.

Suwondo, D. I., \& Sutanto, E. M. (2015). Hubungan Lingkungan Kerja, Disiplin Kerja, Dan Kinerja Karyawan. MANAJEMEN DAN KEWIRAUSAHAAN , 17 (2), 135144.

TRI SASONGKO, A. D. (2016). Pengaruh Gaya Kepemimpinan Situasional, Kompensasi Dan Motivasi Terhadap Kinerja Karyawan Pada PT. Bank Rakyat Indonesia (Persero), Tbk. Cabang Nganjuk. Ilmu Manajemen , 5 (1), 44-59.

Wiratama, I. N., \& Sintaasih, D. K. (2013). Pengaruh Kepemimpinan, Diklat, Dan Disiplin Kerja Terhadap Kinerja Karyawan PDAM Tirta Mangutama Kabupaten Bandung. Jurnal Manajemen , 7 (2), 126-134. 
Halaman ini sengaja dikosongkan 